\title{
Editorial
}

\section{Necropsy in head and neck cancer patient}

The necropsy rate has declined precipitously over the years, in the 1950s 60-80 per cent of in-hospital deaths underwent necropsy, but by the 1980s this had fallen to about 10 per cent. ${ }^{1}$ The reasons are many and varied. The role of necropsy examination must be re-visited, with clinicians being encouraged to increase the number of examinations requested. A recent discouragement to post-mortem has been the negative press following the 'retained organs' scandals at Liverpool and Bristol. Both 'scandals' concerned the retention of body parts of children without parental consent, there appears to have been a 'knock on' effect on adult necropsy examinations. ${ }^{2}$

For necropsies to be worthwhile they must yield hitherto unknown information. The percentage of necropsies that offer new information is referred to as the discordance. In 1972 Bauer and Robbins ${ }^{3}$ found a discordance of 41 per cent, and Burton ${ }^{4}$ in 1998 found a discordance of 44 per cent following necropsy of patients who died with a clinical diagnosis of malignant disease. Neither of these series included any patients with head and neck cancer. The authors ${ }^{5}$ have investigated the discordance in a series of patients who died with a diagnosis of head and neck squamous carcinoma 53 per cent revealed new information. The discordance was equally represented between locoregional disease, that is malignancy above the clavicle, and distant malignancy, either second primary or metastatic disease. This high discordance would suggest necropsy does reveal much useful information that is not known before death.

Does the necropsy have any other role? In 1991 a Joint Working Party ${ }^{6}$ of the Royal College of Pathologists, the Royal College of Physicians of London and the Royal College of Surgeons of England evaluated the autopsy as an audit tool. The recommendations of the working party concluded that the consultant in charge of the case should be responsible for requesting the autopsy, although the consenting can be delegated to a junior member of the team and that a minimum rate of 10 per cent (excluding coroner requested necropsy) should be achieved. Most significantly they indicated that the necropsy rate is a surrogate of quality and that the information gained from the necropsies should feature in the Royal College accreditation procedures.

The necropsy also has a role in clinical governance. ${ }^{7}$ Inadequate investigation of causation of deaths has lead to concerns about death certification, particularly before cremation. The notion that the doctor treating the patient is the one who decides whether a referral to the coroner should be made, may be considered inappropriate. This allows the public to be suspicious that sub-optimal clinical standards may not be uncovered. The most extreme example of this is the Harold Shipman case. ${ }^{8}$ A departmental policy of routinely requesting necropsies may go some way to alleviate such suspicions of cover-up. The necropsy has a role in both postgraduate and undergraduate medical education ${ }^{6}$ and is perceived as the gold standard in clinocopathological correlation. Medical students who attended necropsies found them useful and they cannot be substituted by computer-assisted learning. ${ }^{9}$

Medical reasons for not requesting a necropsy, include poor communication of results and the belief that modern diagnostic scanning can provide all the answers. On the issue of communication, a recent report ${ }^{10}$ of medical staff, revealed that under half were never informed by the pathologist of the result of the necropsy. Attendance at autopsy of a member of the requesting team was also a rare event. A recent report ${ }^{11}$ on computerized tomography and/or magnetic resonance imaging found that they did not significantly predict the result of necropsy in the head and neck cancer patient. The cost of a necropsy examination has been a deterrent in the USA, although not apparently so in the UK.

One of the main concerns recently, has been the revelation that organs were removed from cadavers without the consent of the family or relatives. The report from The Department of Health ${ }^{12}$ found that this was not a widespread practice. They found that of three million post-mortem examinations performed between 1970 and 1999, whole organs were retained in only one per cent. The census took a 'snapshot' of 1999, and found that tissue was retained in 39 per cent of necropsies, with whole organs retained in one per cent. The issue appears to be what is meant by 'retained tissue', and where tissue and organ differ in the minds of the general public. The Department has issued a template of a necropsy consent form, which is designed to eliminate confusion.

Can the necropsy be more focused? One criticism of the post-mortem examination is that time and money are wasted examining the systems that are not pertinent to the cause of death. A direct and focused examination would be more appropriate, directed at solving one or two clinical questions. This 
may be considered although it does run the risk in the head and neck cancer patient of missing comorbid factors, that may be significant.

In conclusion, the value of post-mortem examination in the head and neck cancer patient is high. Relatives should understand when consent for a necropsy is being sought that over half of such examinations provide new information. The authors feel that the relatives of every patient who dies of head and neck cancer should have consent sought for a necropsy.

C. R. Jennings, F.R.C.S., SpR Otorhinolaryngology

P. J. Bradley, F.R.C.S., Consultant Head and Neck Oncologic Surgeon, University Hospital, Queens Medical Centre, Nottingham NG7 5UH.

E-mail: pjbradley@zoo.co.uk

\section{References}

1 Harrison M, Hourihane DO. Quality assurance programme for necropsies.J Clin Pathol 1989;42:1190-3

2 Osborn M, Thompson EM. Asking for consent would halt decline in voluntary necropsies. Br Med J 2001;322:1542-3
3 Bauer FW, Robbins SL. An autopsy study of cancer patients, I: accuracy of the clinical diagnoses (1955 to 1965) Boston City Hospital. J Am Med Assoc 1972;221:1471-4

4 Burton EC,Troxclair DA, Newman WP. Autopsy diagnoses of malignant neoplasms. How often are clinical diagnoses incorrect? J Am Med Assoc 1998;28:1245-8

5 Jennings CR, Bradley PJ. Are autopsies useful? Do premorbid findings predict post-mortem results in head and neck cancer patients? Ann R Coll Surg Eng 2001; (in press)

6 Joint Working Party of the Royal College of Pathologists, Royal College of Physicians of London and the Royal College of Surgeons of England. The Autopsy and Audit. London: Royal College of Pathologists, 1991

7 Leadbetter S, James R. Clinical governance and the coroner. J R Coll Physicians Lond 1999;33:451-3

8 O'Neil B. Doctor as murderer. Br Med J 2000;320:329-36

9 Galloway M. The role of the autopsy in medical education. Hosp Med 1999;60:756-8

10 Lund JN, Tierney GM. Hospital autopsy: standardized questionnaire survey to determine junior doctors' perceptions. Br Med $J$ 2001;323:21-2

11 De Pangher Manzine V, Revignas MG, Brollo A. Diagnosis of malignant tumour: Comparison between clinical and autopsy diagnosis. Hum Pathol 1995;26:280-3

12 Department of Health Report of a Census of Organs and Tissues Retained by Pathology Services in England. London: The Stationery Office, 2001 